\title{
IV.-DISCUSSION.
}

\section{RELATION OF FEELING TO PLEASURE AND PAIN.}

\section{By Hiram M. 8taxley.}

Should the term Feeling be made to include certain states of consciousness which are neither pleasurable nor painful? Or should all such neutral states be designated by some other term? We are concerned here with an important matter of definition which implies an extensive analysis of consciousness with reference to plessure and pain. It will not be difficult to find many so-called feelings which are neutral, or seem to be so; but it is the duty of the psychologist to carefully analyse all such states, and point out the proper use of the term Feeling.

Common observation neglects minute anslysis, and is unreliable when it speaks of certain indifferent states as feelings. When a man speaks of feeling queer, or strange, or bewildered, or surprised, and seys that the state of mind seemed neither agreeable nor disagreeable, we may suspect that by a perfectly natural tendency he is extending the name Feeling to closely-connected states of cognition or will. In identification and definition common observation is for all sciences notoriously untrustworthy, and especially in psychology; so on this question the evidence of language and popular testimony counts for little one way or the other. This is strikingly evident when people speak of feeling indifferent as to some matter, meaning that they have no feeling on the matter. The term Feeling is nsed in such a broad and vegue way that ' $I$ feel indifferent' means ' $I$ am indifferent,' 'I have no feeling'. The mistake here is in using the word Feeling as an equivalent to Ego, or any quality of Ego. A feeling of indifference is no feeling at all. Popular evidence then, I believe, can be no guide in this matter. In passing, I may also say that the very abundant use of analogy by some writers on this subject seems to me ill-advised. Anelogy does very well to bring up the rear, but it is often very useless and confusing as an advance-guard.

Prof. Bain (MrND No. 53) insists that ideas tend to actualise themselves by neutral intensity or excitement, which is feeling; or rather, he says, a "facing-both-ways condition". This last expression is certainly not very helpful or satisfactory. Prof. Bain admits that typical will is incited by pleasure and pain, but he maintains that sometimes, as notably in imitation, will is stimulated by purely neutral excitement or feeling. In the discussion of this subject much has been said about Excitement, and, as Mr. Sully has suggested, this requires careful definition.

35 
Reflection assures us that every mental activity has a certain intensity, and the word Excitement may, in the most general sense, denote this intensity. The intensity may be so slight as to be annoticed by the subject, and remain wholly unindicated to the keenest observer; or it may be so strong as to be perfectly evident to both; or it may be evident to the subject and not to the observer, or vice vers $d$. Thus the obvions division of Excitement from this point of view is into subjective, where it is immediately recognised and felt in the consciousness of the subject, and objective, where it is unnoticed, or noticed only by observer. Classifying by another principle, we may distinguish Cognition-intensity, Feeling-intensity and Will-intensity, and the natural subdivisions under these according to the accepted subdivisions of menteal activities. Excitement is not, however, generally used in the large sense we have just mentioned, but as denoting intensity of a high degree so as to be very noticeable to the subject, or observer, or both.

It is plain that Excitement, as subjective intensity, is the only kind which bears on the question under discussion. It is with excitement as a feeling, vis., the feeling of intensity, and not with excitement as quality of feeling, that is, intensity, that we have to deal, and it is necessary that this distinction be clearly borne in mind. One may be excited but not feel excited, may have intensity of feeling but not feeling of intensity. Using the term, then, as equivalent to feeling of intensity, it is to be noted that it is a reflex or secondary mental state. It is the feeling resulting from consciousness of intensity of consciousness. The intenaity of any consciousness may increase to sach a point that it pushes itself into conscionsness, first es mere recognition of intensity, but immediately and most manifestly as feeling of intensity. In rapid alternations of contrasted states, as of hope and fear, intensity soon rises to such a degree that it forces its way into consciousness as feeling of intensity. This feeling of intensity may be itself either weak or intense. In very reflective natures, the cognition and feeling of intensity may be refles at any power : there may be cognition of the intensity of cognitionof-intensity, \&c., in indefinite regression. Most persons stop with the single step in the regression.

It is evident that as far as excitement is regarded merely as intensity, as a fundamental element in all feeling and mental action, it is a confusion of terms to apply quality to it, to speak of it as either pleasurable, or painful, or neutral. Intensity of mental action has degrees but not quality, just as pitch in sound has degree, but not timbre or quality. Regarding excitement as feeling-of-intensity, it has the general characteristics of all feelings, and is not more likely to be neutral than any other feeling. Taking the case of surprise, which is so frequently instanced as a neutral feeling, let us analyse it with special reference to the excitement as feeling of intensity of cognition. A typical case would be the surprise from hearing thunder in 
January. The presentation is quickly compared with a representation of observed order of facts, and the disagreement of the two marked. This is so far purely cognitive activity; but immediately connected with the perception of disagreement is the forcible recognition of the breaking up of a more or less rigid order. There is a distarbance in cognitive ectivity and the tension breaks into consciousness as excitement, the feeling of intensity. The conflict of a settled conviction with recent presentation intensifies consciousness, and this intensity with the abrupt change in quantity and quality of mental activity breaks into consciousness as intellectual sense of shock accompanied and closely followed by feeling of anpleasentness and pain. It is to be noted that when we come upon the feelingelement in surprise we find pein. Surprise in the strict sense is then the reflex act of conscionsness in which the mind becomes aware of and foels the sudden disturbance and tension set up in itself by the sudden weakening of an established belief. The painful shock hes some relation to the force of the disturbing factor, but is more closely connected with the strength of the belief assailed. The feeling of the disagreement as pain is due to the fact that this disagreement impinges on subjectivity, personel opinion and conviction, and the disturbance will be more or less disagreeable according to the degree of personal interest. Note that by exact statement the feeling is not painful, bat is the pain concomitant or resultant upon the mental perception. The surprise for \& person of rather weak habit of mind and of little generalising power will be almost wholly intellectual. Disagreement will be noted, but not felt. For one of strong intellectual interesto, the surprise will mean definite and acute pain. For a meteorologist who has written a book stating that in this latitude thunder does not occur in January, the surprise might be very grievous. The intellectual element in surprise is emphesised in the statement 'I am surprised,' the feeling-element in 'I feel surprised'. If antecedent states of representation, comparison and inner perception are placed under the term feeling-ofsurprise, we may expect consequent states to be likewise easily confused. When one speaks of being agreeably or disagreeably surprised, the pleasure or pain is not really, however, a part of the surprise. The sense and feeling of intellectual destruction, which constitutes surprise, is so quickly and thoroughly swallowed up in pleasure in having hope realised, or in pain in having fear realised, as the event may prove, that the term is naturally applied to what engrosses attention. Thus, 'It was a very pleasant surprise' means 'The surprise was followed by very pleasant consequences'. When I am surprised by the arrival of an intimate friend whom I supposed a thousand miles away, the mental disagreement, and the pain from conflict of conception and perception, are quickly eliminated by the event according with desire, and by the mind anticipating joys. We see, then, how easily the entecedents and consequents of surprise 
are confounded with surprise itself, which is the reflex act of consciousness recognising and feeling sudden disturbance in intensity, quality and quantity in cognitive activity. I conclude that surprise, as feeling, is pain coloured by cognition of shock and by volition to aroid disturbing element.

Absorption in thought may be attended by what seems to be neutral excitement, but is not really so. The intensity of thought may press into consciousness as a knowledge and foeling of intensity, but so far as it is a feeling it is indubitably pleasure or pain. This pleasure or pain may remain as continuous undertone with frequently repeated intrusion into full consciousness. Careful analysis in this case shows that apparent neatrality results from a strong attendant recognition, or from the natural volitions being quickly overruled by feelings consequent apon other considerations. Intellectual men are not apt to be guided by excitement. Prof. Bain says that imitation is a test-case, that this is a volition which is obviously stimulated by neatral feeling. In some cases imitation seems clearly a mechanical, ideo-motor affair, an instinctive action without either conscions feeling or willing. In all other cases of imitation analysis will show excitant pleasure or pain. As Preyer and others have shown in the case of young children, mimicry arises mainly from pleasure in activity as such, and not from its peculiar quality as imitation. For children, and often for adults, imitation is simply a method of joyous and novel activity. The stimulant in higher grades of imitation is pleasure in attainment. As far as excitement is stimulant, it is, on the general principle before stated, either pleasure or pain. The pleasant feeling of intensity will tend toward continuance of imitative action, the unpleasent toward discontinuance. The pleasurable sense of activity, as inciting and continuing will in imitation, is a good example of excitement as feeling of rolitionintensity.

If rolitional excitement as instanced in imitation, and cognitive excitement as exemplified in surprise and absorption of thought, cannot be termed neutral, it is quite unlikely that we shall find eny neutral feeling-excitement. A person at a horse-race may at first have so small a degree of pleasurable hope and painful fear aroused that the intensity does not force itself into consciousness. The increasingly rapid pendulum-swing of consciousness from hope to fear and back again becomes soon so intense that this objective intensity of feeling forces its way into conscious life se feeling of intensity. This excitement may be mainly regarded as accompaniment, or it may be valued in itself as excitement for excitement's sake. This absorption in the feeling of intensity is eagerly sought for by the ennuye. The devoted theatre-goer often induces both pleasures and paing simply for this resultant feeling of tension which he regards as enjoyable for its own sake. Feeling-excitement in the simpler and earlier form and in this later artificial form is plainly 
pleasure or pain coloured by slight element of cognition as recognition of intensity, and by volition in continuing or in stopping the causative activity.

Bearing in mind the analysis of excitement just made, the true interpretation of several matters which have been suggested is obvious and clear. Mr. Johnson (Murd xii. 82) remarks that very intense mental pleasure and pain tends to run into a state of neutral excitement. This I interpret as the mental law that intensity of any mental activity, of any pleasure or pain, tends to displese this activity by feeling of intensity. This feeling of intensity is indeed neutral as regards previous states-that is, it is not, of course, the feeling whose intensity it feels; but, as I have sought to show, it is nevertheless always pleasure or pain. Again, as to the question whether states of mind equally pleasurable or painful may have different degrees of excitement. If excitement means here subjective excitement, then I answer that they do not have any degree of excitement, for feeling of intensity can never be a quality of the feeling whose intensity is felt. If excitement is the objective form, and refers to the intensity in general, then, as has been before said, it is a confusion in terms to apply the terms pleasure and pain to it. The anticipation suggested by Mr. Johnson as a case of neutral excitement is precisely analogous to the case of excitement at a horse-race, which has been analysed. Mr. Johnson concludes that feeling is not only more or less pleasure or pain but also more or less excitement. The proper way of stating this is : all feelings, including the feeling of excitement, consist of pleasure or pain and have degrees of intensity. Again, let me note the relation of intensity, and consequently feeling of intensity, to qusntity of conscionsness - a subject suggested by Mr. Sully (Mund xii. 252). The fundamental properties of consciousness -quality, quantity, intensity-and also their inter-relations, would be a fruitful theme for extended discussion. I think that the clearing-up of many problems would result from thorough investigation and careful definition in these points; but at present I can only offer a remark or two upon the subject. It is plain that intensity varies with different qualities, that certain finds of mental action are more generally characterised by high degrees of intensity than others. Presentations tend to higher intensities than representations, and pains than plessures. It is noticeable that our psychological nomenclature, both popular and scientific, is mostly concerned with qualities, which shows that quantities and intensities have not received the attention they deserve, and have not been carefully discriminated. A representation of the same house comes up in the minds of two persons, one of whom has lived in it, the other merely seen it several times. Each psychosis is as representative as the other: they have the same quality, but in quantity and intensity they vary greatly. In a single multiplex act of conscionsness, the former embraces a wide reach of detail and association and a 
high degree of intensity which is lacking in the meagre and faint image of the latter. Physiologically, quantity is as the mass of co-ordinate coincident activities of brain in highest centres, and intensity is as the arterial and nervous tension in the highest centres. Intensities msy be equal, and quentities very unequal ; as compare one greatly interested in a game of cards with a versos watching a near relative at a critical moment of illness. Iniensity of pleasurable hope alternating with painful fear may be equal in both cases, but in quantity the larger nature of the friend will greatly exceed. Very quiet natures are often characterised by largeness of quantity of consciousness. Other things being eque!, intensity tends to reduce quantity and obscure quality of consciousness. Quantity, like intensity, may cause a reflex act of consciousness when it becomes so great as to push into consciousness as recognition and feeling of quantity; and as a feeling of largeness, elevation and mental power it is clearly distinguishable from excitement as feeling of intensity. Intensity is dependent on the force or strength by which a mental state tends to persist against other states which may be crowding in, and it is also closely connected with rapidity of mental morement; but it is primarily tension, consciousness at its highest stretch, specially as touching upon interest, an element more or less involved in all conscionsness.

It would seem highly desirable, in order to keep clear the diatinction between intensity and feeling-of-intensity, to restrict the term Excitement to the latter meaning, and substitute the general term Intensity for all objective excitement 80-called. It is also greatly to be desired that the reflex states which arise from sudden or great changes in quality, quantity and intensity of consciousness, and which are commonly termed feelings, should receive more general attention from peychologists than heretofore. I have in this paper essayed something in this direction, bat it is a very large field, and comparatively unexplored.

However, so far as the problem of feeling as indifference is concerned, onough has been said on Excitement and Intensity, and I shall now consider Neutralisation as giving neutral feeling, a method suggested by Mr. Johnson (MIND xiii. 82), and developed by Miss Mason (xiii. 253). Does a feeling, neutral as regards pleasure and pain, result from the union in one consciousness of a pleasure and pain of equal intensities? Is there a composition of equal mental forces вo that resultant equals zero? Such a question implies a clear apprehension of what is meant by being in consciousness, and as to the possibility of perfect coincidence and equality in mental activities. It is plain that so far as consciousness is linear, neutralisation cannot occur. Where there is but one track, and but one train at a time, collision is impossible. Mental states often appear coexistent while they are really consecutive. It is doubtful whether pain from toothache and pleasure from music ever appear in absolute synchronism in consciousness, but they may alternate so rapidly sometimes as to $\because \therefore$. 
appear synchronous to uncritical analysis. To a man drowning, a lifetime of conscions experience seems condensed into a few seconds. This means a consciousness made very sensitive and very rapid in its movement, and which acts like a camera taking pictures with a lightning-shutter. Eren if a plessure and pain did coincide, it is probable that in no case would they be exactly equal. In mental life as in organic life every product has an individuality : as every leaf differs from every other leaf, so every mental state is on completest observation sui generis. This is evidently a most delicate investigation, but I doubt whether it can ever be shown that two equal plessures and pains ever appear in the same sense in consciousness at the same time. Practically equal pleasures and pains in consecutive conscionsness lead to vacillation, and the secondary pain of alternation and excitement drives intelligent agents to new activity, or in stupid agents the alternation may be carried to exhaustion.

It is undoubtedly true that consciousness, in all the higher forms at least, is a complex; yet full and complete consciousness is probably of one element only, and the remaining portion of the nexus grades off into subconsciousness and unconscionsness. There is a network of coexistent states of consciousness in different degrees in mutual reaction, each striving for dominance but only one at a time reaching it. Some portions of the nexus, as Ego-tone, are quite permanent elements. The light of a large and brilliant consciousness may illumine a considerable area, but brightness most certainly diminishes in rapid ratio as the distance increases from attention, the single point of greatest illumination. A highly developed brain may sustain a highly complex consciousness, but it is only at the point of highest functional activity that we find the physiological basis of a full consciousness. While high grades of mental life are so complex, we do not find anywhere a mental compound. Two diverse or opposite elements never combine into a compound which is totally unlike either. Close analysis will fail to reveal any process of neutraliaation or combination whereby we experience neutral states of feeling.

I have endeavoured to set forth the real nature of certain socalled neutral feelings; but at bottom the question is, as was at first intimated, a matter of definition. Is it best to restrict the term Feeling to pleasurable and painful states of consciousness, or is it advisable for clearness and definiteness to widen the use of the term so as to include certain neutral states? From such analysis as has been made, I donbt the advisability. Appeal in such matters must always be made to analysis, and the advantage must be shown for a concrete example. The a priori idea or general impression that pleasure and pain is too small a basis for all feeling has no real weight. Moreover, it must always be borne in mind that psychology like all other sciences deals only with phenomena and not with essences, not with mind bat with mental manifestations, not with feeling as mental entity having 
properties, being plessurable, painful, \&c., but with these qualities in and for themselves. Thus the metaphysical fallacy hidden in such common expressions as pleasurable and painful feelings is to be constantly guarded against. The feeling is not pleasurable or painful, but is the plessure or the pain. The feeling hes no independent being apart from the attributes which in common usage are attached to it, nor is there any general act of consciousness with which these properties are to be connected. As indicated at the beginning of this paper, this common tendency has its psychological besis in the bringing under the term Feeling some of the more permanent elements of consciousness-especially the Ego-sense-which stand for metaphysics as beings and entities having properties. Knowledge, Feeling, Will, are for nominalistic science simply general terms denoting the three groups of mental phenomena which seem to stand off most clearly and fundamentally from each other, and Pleasure and Pain are most clearly and fundamentally set over against Knowing and Willing. It does not seem that Prof. Bain and others have made plain to us any better differentia.

If this definition of Feeling seems the best that descriptive classification can give us, it is certainly enforced by genetic considerations. The key to a really scientific classification lies in the history of mind in the individual and race. The great progress in psychology is not to be attained by the psychologist continually reverting to his own highly developed consciousness, but, as in all sciences, the study of the simple must be made to throw light upon the complex. Mentelity like life is a body of phenomena whose forms cannot be separated by hard and fast lines into orders, genera, species; but there is a continuous development of radical factors. In the earliest forms of mind we find the most radical distinctions most clearly and simply set forth, and what Feoling is at first, it is by continuity of development the same for ever after. The earliest indications of conscions life show merest trace of apprehension of object, some organic pleasure and pain, considerable striving and effort. Mental evolution, like all evolution, is not by the elimination but by the expansion of its primal factors; and by the continuons amplification and intensification of these the highest development is reached. Plessure and pain remain then for all consciousness as constant factors, and if the term Feeling is to indicate one element in tripartite mind it must be held to this meaning of pleasure and pain. Pleasure and pain in their most complicated colourings from developed knowledge and will, and in their most subtle interactions, remain true to the primal type; and when we find a state of consciousness in which neither is a dominant factor, we had best denote it by some other term than Feeling. This evolutionary reason seems to me the strongest one for making the term Feeling signify states of pleasure or pain, and, as I have suggested (MIND xi. 74-5), a genetic classification of the feelings must proceed upon this basis. 